CASE REPORT

\title{
Fatal Pasteurella dagmatis peritonitis and septicaemia in a patient with cirrhosis: a case report and review of the literature
}

\author{
B D Ashley, M Noone, A D Dwarakanath, H Malnick
}

J Clin Pathol 2004;57:210-212. doi: 10.1136/icp.2003.7419

\begin{abstract}
Pasteurella species cause zoonotic infections in humans. Human pasteurella infections usually manifest as local skin or soft tissue infection following an animal bite or scratch. Systemic infections are less common and are limited to patients at the extremes of age or those who have serious underlying disorders, including cirrhosis. Most human pasteurella infections are caused by the multocida species. We report a case of Pasteurella dagmatis peritonitis and septicaemia in a patient with cirrhosis. The infection followed a scratch inflicted by a pet dog. Despite appropriate antibiotic treatment the infection proved fatal. Spontaneous bacterial peritonitis caused by $P$ dagmatis has not been reported previously. Pasteurella dagmatis is a relatively recently described species, which is rarely reported as a human pathogen. This species may be misidentified unless commercial identification systems are supplemented by additional biochemical tests.
\end{abstract}

A 56 year old woman with biopsy confirmed alcoholic cirrhosis and known portal hypertension with ascites was admitted to hospital complaining of worsening ankle swelling and abdominal distension, abdominal pain, and spontaneous bruising over the previous week. She was at that time drinking one third of a bottle of sherry (seven to eight units of alcohol) each day. She reported having been scratched on her left arm by her dog one week previously.

She was found to be febrile $\left(37^{\circ} \mathrm{C}\right)$ and jaundiced with bilateral peripheral oedema to her mid thighs. Her pulse rate was 95 beats/minute, her blood pressure was 115/45 mm Hg, and she had a tender abdomen distended with ascites and covered in echymoses. Her left arm was erythematous and warm and the overlying skin was indurated.

Laboratory tests showed a normal white blood cell count $\left(8.2 \times 10^{9}\right.$ /litre; normal range, $\left.4 \cdot 0-10 \cdot 0\right)$, deranged liver function tests (bilirubin, $357 \mu \mathrm{mol} /$ litre; normal range, 0-17; alkaline phosphatase, 153 U/litre; normal range, 40-130; aspartate aminotransferase, $48 \mathrm{U} /$ litre; normal value, $>30$ ), and abnormal synthetic liver function (albumin, $31 \mathrm{~g} / \mathrm{litre}$; normal range, 35-50 g/litre; prothrombin time, 32 seconds; normal range, 10.9-14.5).

Abdominal paracentesis yielded blood stained fluid. The ascitic fluid protein was $62 \mathrm{~g} /$ litre (indicating an exudate), albumin was $45 \mathrm{~g} / \mathrm{litre}$, and the red cell count was $>2160 / \mu \mathrm{l}$. The sample contained no white blood cells and the Gram stain revealed no organisms.

Treatment was begun with intravenous benzylpenicillin, ciprofloxacin, and metronidazole.

Over the course of the next few hours the patient's condition worsened with a high fever, tachycardia, and hypotension, and despite vigorous attempts at resuscitation she deteriorated very rapidly and died 24 hours after admission.

\section{MICROBIOLOGY}

Specimens of blood were inoculated into aerobic (vented) and anaerobic (unvented) media (BacT-Alert; Cambridge, UK). Gram negative coccobacilli were isolated from both aerobic and anaerobic bottles after nine and 12 hours, respectively. Ascitic fluid was inoculated into blood culture media as above and also cultured directly on to MacConkey agar, 5\% horse blood in Columbia agar (Oxoid, Basingstoke, UK), and chocolate blood agar incubated at $37^{\circ} \mathrm{C}$ in air and $5 \% \mathrm{CO}_{2}$, in addition to Anaerobe Agar (BioConnections, Shipley, UK) incubated at $37^{\circ} \mathrm{C}$ in an anaerobic cabinet (Don Whitley, Shipley, UK). Direct culture and enrichment cultures of ascitic fluid also grew a Gram negative coccobacillus. These isolates were identified using API 20 NE (BioMerieux UK Ltd, Basingstoke, UK). A presumptive identification of Pasteurella multocida was made and the isolate was referred to the laboratory of health care associated infection, Health Protection Agency, Colindale, London, UK. Analysis was carried out using the Sherlock microbial identification system (MIDI Inc, Newark, Deleware, USA), with additional biochemical tests, and the isolate identified as Pasteurella dagmatis. The organism was sensitive in vitro to penicillin, gentamicin, and ciprofloxacin (VITEK system; Bio-Merieux UK Ltd).

\section{DISCUSSION}

Spontaneous bacterial peritonitis occurs in approximately $15 \%$ of patients with cirrhotic liver disease and ascites. ${ }^{1}$ The causative organisms are usually enteric Gram negative bacilli or streptococci. ${ }^{1-3}$ We report the first case of spontaneous bacterial peritonitis and septicaemia caused by an unusual organism, $P$ dagmatis, following a scratch from a domestic animal.

Pasteurella species are Gram negative coccobacilli that commonly colonise the oropharynx of healthy domestic animals-especially cats (90\%) and dogs (66\%)..$^{4-6}$ They are well recognised as veterinary pathogens, and over recent years, increasingly commonly as a cause of human infection. Pasteurella multocida is the most frequently reported species.

In 1985, members of the genus pasteurella were reclassified into 11 species including $P$ multocida and $P$ dagmatis. ${ }^{7}$ Pasteurella multocida and $P$ dagmatis cannot be distinguished morphologically and the API 20 NE system, like most commercially available identification systems, cannot distinguish between the two because $P$ dagmatis is not in its current database. This explains why the organism in our patient was not immediately recognised as $P$ dagmatis. It may also explain the low frequency of reports of $P$ dagmatis infection. A positive urease test distinguishes $P$ dagmatis from $P$ multocida, but 


\section{Take home messages}

- We report a case of Pasteurella dagmatis peritonitis and septicaemia in a patient with cirrhosis, which occurred after she was scratched by a pet dog

- Despite appropriate antibiotic treatment the patient died of the infection

- Pasteurella dagmatis is a relatively recently described species, which is rarely reported as a human pathogen, and bacterial peritonitis caused by this organism has not been reported previously

- This species may be misidentified unless commercial identification systems are supplemented by additional biochemical tests

- Because of the high mortality rate, appropriate antibiotic treatment should be instituted as soon as possible, and first line antibiotic treatment should include a $\beta$ lactam agent

confident speciation of pasteurella will require further biochemical tests. Pasteurelladagmatis is indole production positive, ornithine decarboxylase and ONPG negative, and positive for acid production from glucose, maltose, and sucrose, but mannitol and lactose negative. Furthermore, it should be noted that API 20 NE may misidentify the morphologically similar Haemophilus spp as a species of pasteurella. ${ }^{8}$

Over a six year period the identification services, Health Protection Agency, Colindale received 56 isolates of Pasteurella spp for identification. The species identified were $P$ dagmatis $(\mathrm{n}=5), P$ multocida $(\mathrm{n}=44), P$ canis $(\mathrm{n}=2)$, and $P$ pneumotropica $(\mathrm{n}=1)$. Four isolates could not be identified to species level.

Pasteurella infection usually manifests as a local skin or soft tissue infection following an animal bite or scratch. The most common complication is abscess formation or tenosynovitis. ${ }^{9-11}$ Less commonly, infection occurs in patients who have had only casual exposure to farm animals or pets, with the most common site of the infection in these cases being the respiratory tract. ${ }^{9-11}$ In a small number of cases, infection occurs in individuals who have apparently had no animal exposure and develop a variety of systemic infections such as bacteraemia, meningitis, brain abscesses, spontaneous bacterial peritonitis, or intra-abdominal abscesses. Even without a history of animal exposure it is thought that an animal reservoir is the major source of pasteurella infections. ${ }^{9-11}$

"Speciation may not influence clinical management, but accurate identification of pasteurella to species level will help characterise the prevalence, antibiotic susceptibilities, and pathogenic potential of Pasteurella dagmatis"

Life threatening systemic infection is uncommon and usually only occurs in the immunocompromised, ${ }^{12}$ including patients with cirrhosis, and those at the extremes of age.

Penicillin is the drug of choice for $P$ multocida infections. The organism is sensitive in vitro to chloramphenicol, tetracycline, and the fluoroquinolones, which may be suitable alternatives in the case of penicillin allergy. Pasteurella dagmatis appears to have a similar antibiotic susceptibility pattern, but information in the literature is scanty. Even with appropriate treatment, $P$ multocida bacteraemia carries an overall mortality rate of $31 \%{ }^{13}$
In our patient, $P$ dagmatis caused spontaneous bacterial peritonitis, septicaemia, and ultimately death. In patients with cirrhosis and ascites, only one third of cases of spontaneous bacterial peritonitis are caused by non-enteric organisms. ${ }^{14}$ Pasteurella multocida as a causative organism is particularly rare, with only 15 documented cases. ${ }^{15-28}$ There are no previous reports of $P$ dagmatis in this setting.

Pasteurella infection should be suspected as a cause of spontaneous bacterial peritonitis and septicaemia in patients immunocompromised by cirrhosis, especially if there is a history of exposure to domestic animals. In view of the high mortality, appropriate antibiotic treatment should be instituted as soon as possible, and first line antibiotic treatment should include a $\beta$ lactam agent. Speciation may not influence clinical management, but accurate identification of pasteurella to species level will help characterise the prevalence, antibiotic susceptibilities, and pathogenic potential of $P$ dagmatis.

\section{Authors' affiliations}

B D Ashley, M Noone, A D Dwarakanath, University Hospital of North Tees, Hardwick, Stockton on Tees TS19 8PE, UK

H Malnick, Laboratory of Health Care Associated Infection, Health

Protection Agency, London NW9 5HT, UK

Correspondence to: $\operatorname{Dr} M$ Noone, University Hospital of North Tees, Hardwick, Stockton on Tees TS19 8PE, UK; noone@littleri.freeserve.co.uk

Accepted for publication 22 September 2003

\section{REFERENCES}

1 Garcia-Tsao G. Spontaneous bacterial peritonitis. Gastroenterol Clin North Am 1992;21:257-75.

2 Conn HO, Fessel MJ. Spontaneous bacterial peritonitis in cirrhosis: variations on a theme. Medicine 1971;50:161-97.

3 Curry N, McCallum RW, Guth PH. Spontaneous peritonitis in cirrhotic ascites. Am J Dig Dis 1974;19:685-92.

4 Smith JE. Studies on Pasteurella septica. II. Some cultural and biochemical properties of strains from different host species. J Comp Pathol Ther 1958;68:315.

5 Owen CR, Buker ED, Bell JE. Pasteurella multocida in animals' mouths. Rocky Mt Med J 1968;65:45-6.

6 Bailie WE, Stowe EC, Schmitt AM. Aerobic bacterial flora and nasal fluids of canines with reference to bacteria associated with bites. J Clin Microbiol 1978;7:223-31.

7 Mutters R, lhm P, Pohl S, et al. Reclassification of the genus Pasteurella trevisan 1887 on the basis of deoxyribonucleic acid homology, with proposals for the new species Pasteurella dagmatis, Pasteurella canis, Pasteurella stomatis, Pasteurella anatis and Pasteurella langaa. Int J Syst Bacteriol 1985;35:309-22.

8 Hamilton-Miller JM. A possible pitfall in the identification of Pasteurella spp. with the API system. J Med Microbiol 1993;39:78-9.

9 Furie RA, Cohen RP, Hartman BJ, et al. Pasteurella multocida infection: report in urban setting and review of spectrum of human disease. NY State J Med 1980;80:1597-602.

10 Jones FL Jr, Smull CE. Infections in man due to Pasteurella multocidaimportance of human carrier. Pa Med J 1973;76:41-5.

11 Weber DJ, Wolfson JS, Swartz MN, et al. Pasteurella multocida infections: report of 34 cases and review of the literature. Medicine (Baltimore) 1984;63:133-54.

12 Stein AA, Fialk MA, Blevins A, et al. Pasteurella multocida septicaemia: experience at a cancer hospital. JAMA 1983;249:508-10.

13 Raffi F, Barrier J, Baron D. Pasteurella multocida bacteremia: report of thirteen cases over twelve years and review of the literature. Scand J Infect Dis 1987; 19:385-93.

14 Wilcox CM, Dismukes WE. Spontaneous bacterial peritonitis. A review of pathogenesis, diagnosis and treatment. Medicine (Baltimore) 1987;66:477-56.

15 von Neumann A, Rochricht C. Septikamia durch Pasteurella multocida bei postnekrotischer lebserzirrhose. Dtsch Ges Wesen 1972;27:2341-3.

16 Palutke WA, Boyd CB, Carter GR. Pasteurella multocida in a patient with cirrhosis. Am J Med Sci 1973;266:305.

17 Heyworth MF, Stainforth JN, Wright R. Pasteurella multocida septicemia associated with chronic liver disease. BMJ 1975:4:733-4.

18 Correia JP, Conn HO. Spontaneous bacterial peritonitis in cirrhosis: endemic or epidemic? Med Clin North Am 1975;59:963.

19 Gerding DN, Khan MY, Ewing JW, et al. Pasteurella multocida peritonitis in hepatic cirrhosis with ascites. Gastroenterology 1976;70:413-15.

20 Jacobson JA, Miner P, Duffy O. Pasteurella multocida bacteremia associated with peritonitis and cirrhosis. Am J Gastroenterol 1977;68:489. 
21 Patton F, Duman M Cannon NJ. Pasteurella multocida septicaemia and peritonitis in a cirrhotic cock trainer with a pet pig. N Engl J Med 1980;303:1126.

22 Szpak CA, Woodard BH, White JO, et al. Bacterial peritonitis and bacteremia associated with Pasteurella multocida. South Med J 1980:73:801.

23 Vakil N, Adiyody J, Treser G. Pasteurella multocida septicemia and peritonitis in a patient with cirrhosis: case report and review of the literature. Am J Gastrenterol 1985;80:565-8.

24 Honberg PZ, Frederiksen W. Isolation of Pasteurella multocida in a patient with spontaneous peritonitis and liver cirrhosis. Eur J Clin Microbiol 1986;6:340-2.
25 Navarro V, Ferreruela R, Berbegal J. Peritonitis primaria espontanea por Pasteurella multocida. An Med Interna 1994;11:47-8.

26 Fernandez-Esparrach G, Mascaro J, Rota R, et al. Septicaemia, peritonitis, and empyema due to Pasteurella multocida in a cirrhotic patient. Clin Infect Dis 1994; 18:486

27 Koch CA, Mabee CL, Robyn JA, et al. Exposure to domestic cats: risk factor for Pasteurella multocida peritonitis in liver cirrhosis? Am J Gastroenterol 1996;91:1447-9.

28 Bilbao Garay J, Zapatero Gaviria A, Perea Lopez, et al. (Spontaneous peritonitis in a cirrhotic patient with a cat: Pasteurella multocida infection of the ascitic fluid). Rev Esp Enferm Dig 1997;89:786-9. 